successful cooperation with target institutions in Serbia in the next years. We would like to improve the cooperation with medical faculties and become a part educational program. And the PEP was the best way to achieve this aim Objectives: The aims of this knowledge transfer programme were for us to: 1. Fundraising

- Learn how to gather more voluntary contributions of money and other resources. Following the knowledge transfer visits we will organise a seminar to disseminate information with the representatives of all our branches. After the seminar our activists will have been trained to collect money for different activities. Those activities will attract more members and provide better life for people with RMDs.

2. Patient Expert Program

- Implement the Patient Expert Program. The implementation of this program would strengthen the connections with medical institutions, provide first/ hand knowledge for future doctors, provide better care for RMDs patients in the future. The PEP will allow the organization to collaborate closer with the universities, the doctors, researchers, health professionals.

3. Cooperation among sister organisations

Develop strong relationships with the sisters EULAR organisations.

Methods: From $4^{\text {th }}$ September $-8^{\text {th }}$ September 2018 we visited Swedish Rheumatism Association in Stockholm in order to gain insight into the structure and activities of their association.

From $14^{\text {th }}$ October-16 $6^{\text {th }}$ October 2019 Swedish delegation (president, two trainers and secretary) visited Serbian association for rheumatic diseases. It was organized the two-days PEP training as well as the visits to relevant institutions.

From 23th January-26 ${ }^{\text {th }}$ January 2020 two trainers from Sweden came to Serbia in order to hold the exams.

Results: Association of Rheumatic Diseases Patients of the Republic of Serbia now has six Patient Experts for RA. They will be involved in the education of future doctors through the lectures within the subject Intern Medicine.

ORS improved cooperation with Faculty of Medicine in Belgrade, as well as, with Ministry of Health.

Conclusion:

- We achieve to have six Patient Experts. Unofficially right now we have confirmation how they will be included in the education of future doctors through the lectures within the subject Intern Medicine in next school year at the Belgrade University

- We reduced contribution of the pharmaceutical companies of our income for $10 \%$ to our budget.

- We increased donations from personal donators In past year.

Disclosure of Interests: None declared

DOI: 10.1136/annrheumdis-2020-eular.4864

\section{OP0261-PARE BIOSIMILAR SWITCHING PROCESS - UK PATIENTS' EXPERIENCE STUDY}

C. Jacklin ${ }^{1}$, A. Bosworth ${ }^{2}$ on behalf of Sally Dickinson, Helen McAteer, Ailsa Bosworth, Sarah Berry, Clare Jacklin. ${ }^{1}$ National Rheumatoid Arthritis Society, Maidenhead, United Kingdom; ${ }^{2}$ National Rheumatoid Arthritis Society, Maidenhead, United Kingdom

Background: The introduction of 4 adalimumab biosimilars was challenging for the health service and patients alike. A group of patient organisations representing rheumatology, dermatology and gastroenterology patients worked with NHS England in producing materials for disseminating information to prescribers and patients to ensure smooth and appropriate transition to biosimilar products from the originator product as appropriate. These patient groups wanted to know how the 'switch' process was implemented and if shared decision making was practiced.

Objectives: To gather patient feedback on biosimilar switch process and report findings back to NHS England as well as provide the patient organisations information to develop any future resources to help improve patient and physician shared decision making.

Methods: A working group of the 4 organisations collaborated on designing an online survey asking questions around how the individual was communicated with regarding their treatment being switched to a biosimilar; was there any choice or perceived input into the decision making process; how queries or issues were handled and overall satisfaction on how the individual felt their personal preferences/needs were met.

Results: 899 useable responses were gathered representing 52\% Rheumatology patients; $42 \%$ Gastroenterology patients and 5\% Dermatology patients with remaining $1 \%$ more complex specialties. More than half of patients were not asked for their consent before their treatment was switched to a biosimilar of adalimumab with only $40 \%$ giving consent $7 \%$ couldn't remember or were unsure if consent was given. $75 \%$ were not at all satisfied or not satisfied with the ability to decline being switched with only $12 \%$ feeling that they had been given an option to decline being switched.
Conclusion: Shared Decision Making (SDM) needs to be put into action not just words. There is a clear majority that are dissatisfied with the communication they had prior to the switch and are very dissatisfied with the lack of patient engagement in the decision-making process. NRAS, NASS, Crohn's \& Colitis UK and the Psoriasis Association will continue to collaborate with NHS England and other stakeholders as appropriate to make Shared Decision Making a reality not just rhetoric.

Acknowledgments: National Axial Spondyloarthritis Society UK; Crohns' \& Colitis UK;

Psorarsis Association, UK; National Rheumatoid Arthritis Society

Disclosure of Interests: Clare Jacklin Grant/research support from: NRAS has received grants from pharmaceutical companies to carry out a number of projects, Consultant of: I have been paid a speakers fee to participate in advisory boards, in house training of staff and health professional training opportunities, Speakers bureau: Various pharma companies, Ailsa Bosworth Speakers bureau: a number of pharmaceutical companies for reasons of inhouse training, advisory boards etc.

DOI: 10.1136/annrheumdis-2020-eular.2362

\section{Disease consequences}

\section{OP0262-HPR COST OF ILLNESS IN PATIENTS WITH PSORIASIS AND PSORIATIC ARTHRITIS. COEPSO STUDY}

S. Castañeda ${ }^{1}$, E. Vicente ${ }^{2}$, M. Llamas Velasco ${ }^{3}$, J. Sanchez Perez ${ }^{3}$, J. Pardo $^{4}$,

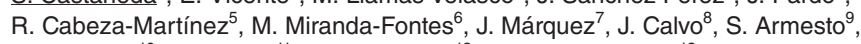
I. Belinchón ${ }^{10}$, A. Gómez ${ }^{11}$, M. D. Miranda ${ }^{12}$, S. Martinez Pardo ${ }^{13}$, L. MerinoMeléndez ${ }^{14}$, M. A. Casado ${ }^{15}$, M. Yébenes ${ }^{15}$, A. Casado ${ }^{15}$. ${ }^{1}$ H.U. de la Princesa, IIS-Princesa, Cátedra UAM-ROCHE, EPID-Future, Rheumatology, Madrid, Spain; ${ }^{2}$ H.U. de la Princesa, IIS-Princesa, Rheumatology, Madrid, Spain; ${ }^{3}$ H.U. de la Princesa, IIS-Princesa, Dermatology, Madrid, Spain; ${ }^{4}$ H.G.U. Santa Lucía, Cartagena, Spain; ${ }^{5}$ H.U. Puerta de Hierro Majadahonda, Madrid, Spain; ${ }^{6}$ H.U. Río Hortega, Valladolid, Spain; ${ }^{7}$ H.G. Jerez de la Frontera, Cádiz, Spain; ${ }^{8}$ H.U. Araba, Vitoria, Spain; ${ }^{9}$ H.U. Marqués de Valdecilla, Santander, Spain; ${ }^{10}$ H.G.U. Alicante, Alicante, Spain; ${ }^{11}$ H.U. Infanta Sofía, Madrid, Spain; ${ }^{12}$ H.G. San Agustín de Linares, Jaen, Spain; ${ }^{13} \mathrm{H}$. Mutua de Terrassa, Barcelona, Spain; ${ }^{14} \mathrm{H}$. San Pedro, Logroño, Spain; ${ }^{15}$ Pharmacoeconomics \& Outcomes Research Iberia (PORIB), Madrid, Spain

Background: Psoriasis (Ps) and psoriatic arthritis (PsA) have a major impact on patients' health-related quality of life. Cost of illness of patients with Ps, PsA and both diseases (PsA+Ps) is an important subject as they are associated with a substantial economic impact, with implications from a health management perspective.

Objectives: To describe the economic burden of direct non-healthcare and indirect resources of patients with Ps, PsA and PsA+Ps in Spain.

Methods: COEPSO ("Evaluation of Costs in patients with Psoriatic Disease") was an observational, retrospective, cross-sectional study performed in 22 Spanish centers (17 Dermatology and 14 Rheumatology Services), from February 2017 to February 2018, including moderate to severe Ps and PsA patients (with or without Ps), naive to biologics. Direct non-healthcare (social services, home care, physical adaptations, private health and non-health professionals, non-reimbursed and non-pharmaceutical therapies), indirect (loss of productivity) and total costs (direct non-healthcare and indirect costs) related to the disease during the previous year to the study were obtained. Unitary costs $(€$, 2018) were calculated: out-of-pocket costs were specified directly by patients and loss of productivity costs by means of average salaries based on occupation specified by patients. The information was collected through a case report form filled out by the investigators and a telephone survey administered to the patients.

Results: A total of 318 patients were included (196 Ps; 43 PsA and 79 PsA+Ps), mean age 48.7 years and $51.3 \%$ males. Metabolic syndrome was the most frequent comorbidity in all groups. The average annual total cost per patient was $1,042.71 €$ (SD 3,817.55), 1,137.84€ (SD 3,070.39) and 1,830.26€ (SD 5,835.81) for Ps, PsA and PsA+Ps, respectively. The average annual direct non-healthcare cost per patient was 749.57€ (SD 2,393.77), 750.50€ (SD 1,641.82) and $1,247.56 €$ (SD 4,467.19) for Ps, PsA and PsA+Ps, respectively. The average annual indirect cost per patient was 293.14€ (SD 2,855.27), 387.35€ (SD $2,409.63$ ) and 582.71€ (SD 3,842.12) for Ps, PsA and PsA+Ps, respectively. Patients with combined PsA+Ps had higher annual total cost (direct non-healthcare and indirect costs) than patients with only one of these manifestations separately $(75.5 \%$ and $60.9 \%$ above patients with $\mathrm{Ps}$ and $\mathrm{PsA}$, respectively). Total costs in patients with Ps and PsA were similar. Direct non-healthcare costs represent between $66.0 \%$ (patients with PsA) to $71.9 \%$ (patients with Ps) of total cost. Indirect costs represent between $28.1 \%$ (patients with Ps) to $34.0 \%$ (patients with PsA) of total cost. 